\title{
RANCANG BANGUN SISTEM INFORMASI PEMBIAYAAN PERJALANAN DINAS PADA DINAS KESEHATAN KOTA PEMATANGSIANTAR
}

\author{
Ajeng Christin Putri Girsang 1, Dedi Suhendro ${ }^{2}$, \\ Sufiana Indah Sari Siregar ${ }^{3}$ \\ Program Studi Komputerisasi Akuntansi \\ AMIK Tunas Bangsa Pematang Siantar \\ Jl. Jend Sudirman Blok A, No. 1,2 dan , Kota Pematangsiantar, \\ Sumatera Utara \\ Ajenggirsang@gmail.com ${ }^{1}$ \\ Dedi.su@amiktunasbangsa.ac.id ${ }^{2}$
}

\begin{abstract}
Abstrak
Abstrak - Didalam suatu instansi pemerintah perjalanan dinas merupakan suatu kegiatan yang sangat sering dilakukan oleh pegawai ataupun pejabat dalam instansi tersebut. Sehingga sangat diperlukannya laporan pertanggungjawaban dari setiap anggaran yang telah dikeluarkan oleh pemerintah untuk membiayai perjalanan dinas tersebut. Dalam mengolah anggaran dan membuat laporan keuanga Dinas Kesehatan Kota pematangsiantar menggunakan microsoft excel yang menurut penulis kurang efektif dalam penggunaanya. Sehingga salah cara untuk mengatasi hal tersebut penulis merancang suatu sistem menggunakan aplikasi Microsoft Visual Studio 2010 sebagai bahasa pemrograman dan juga menggunakan My Sql sebagai penyimpanan database. Didalam penulisan perancangan ini penulis menggunakan metode perancangan sistem seperti DFD,ERD Normalisasi dan RAT.
\end{abstract}

Kata Kunci : MicrosoftVisual Studio 2010, MySql,Perjalanan Dinas

\section{Pendahuluan}

Didalam suatu instansi pemerintah perjalanan dinas merupakan suatu kegiatan yang sangat sering dilakukan oleh pegawai ataupun pejabat dalam instansi tersebut. Biaya perjalanan dinas biasanya dibayar dengan cara limpsum (di awal 


\section{Rancang Bangun Sistem Informasi Pembiayaan Perjalanan Dinas pada Dinas Kesehatan Kota Pematangsiantar}

perjalanan dinas), dengan cara reimbursement/penggantian ataupun dengan cara pemberian uang muka. Biaya perjalanan dinas terdiri dari 3 komponen yaitu biaya transportasi, biaya akomodasi dan uang saku. Oleh karena itu setiap biaya yang dikeluarkan oleh suatu instansi dalam pembiayaan perjalanan dinas dibutuhkan suatu pertanggungjawaban pengeluaran yang harus di laporkan kepada pimpinan.

Adapun arti dari perjalanan dinas jabatan adalah perjalanan dinas melewati batas Kota dan/atau dalam Kota dari tempat kedudukan ke tempat yang dituju, melaksanakan tugas, dan kembali ke tempat kedudukan semula di dalam negeri. Sedangkan perjalanan dinas pindah adalah perjalanan dinas dari tempat kedudukan yang lama ke tempat kedudukan yang baru berdasarkan surat keputusan pindah (Aginta 2013). menyatakan prosedur akuntansi pengeluaran kas meliputi serangkaian proses, baik manual maupun terkomputerisasi mulaI dari pencatatan, penggolongan dan peringkasan transaksi dasar atau kejadian keuangan, hingga pelaporan keuangan dalam rangka pertanggungjawaban pelaksanaan APBD yang berkaitan dengan pengeluaran kas pada SKPD dan SKPKD (Maharani A. Onibala and Kalangi 2014).

Penulis mengajukan sebuah rancang bangun sistem menggunakan aplikasi pemrograman V.B Net Database my $S Q L$, dimana sistem ini dapat diintegrasikan dengan berbagai macam pemrograman bahasa dan mudah untuk digunakan. Diharapkan dengan adanya sistem ini dapat memudahkan dalam pembuatan laporan perjalanan dinas, sehingga penggunaan waktu dalam pembuatan laporan lebih cepat dan terstruktur. XAMPP adalah perangkat lunak bebas, yang mendukung banyak system operasi, merupakan kompilasi dari beberapa program. Fungsinya adalahsebagai server yang berdiri sendiri (localhost), yang terdiri atas program Apache HTTP Server, MySQL database, dan penerjemah bahasa yang ditulis dengan bahasa pemrograman PHP dan Perl (Priyanti and Iriani 2013).

Dalam membuat perancangan tersebut penulis menggunakan metode Perancangan Sistem ERD, DFD, Flowchart. Entity Relationship Diagram merupakan notasi grafis dalam pemodelan data konseptual yang mendeskripsikan hubungan antara 
penyimpanan (Suhendro 2017). Data Flow Diagrams (DFD) menggambarkan komponen sistem, aliran data di antara komponen sistem tersebut, sumber data, tujuan, dan penyimpanan data (Suhendro 2017). Flowchart adalah suatu bagan dengan simbol-simbol tertentu yang menggambarkan urutan proses secara mendetail dan hubungan antara suatu proses (instruksi) dengan proses lainnya dalam suatu program (Suhendro 2017). MySQL adalah sebuah perangkat lunak sistem manajemen basis data SQL (bahasa Inggris: database management system) atau DBMS yang multithread, multi-user, dengan sekitar 6 juta instalasi di seluruh dunia (Ramadhani, Anis, and Masruro 2013).

\section{Metode Penelitian}

Untuk memperoleh data yang diperlukan penulis untuk penelitian ini, dilakukan dengan 3 cara :

a. Pengamatan (Observasi) langsung pada Kantor Dinas Kota Pematangsiantar.

b. Melakukan wawancara terhadap bendahara keuangan yang menerima anggaran perjalanan dinas tersebut.

c. Melakukan studi keperpustakaan untuk mengumpulkan data dan teori-teori yang diperlukan.

\section{Hasil dan Pembahasan}

\section{A. Tahap Perancangan Basis Data}

Pada tahap perancangan basis data, tampilan sistem realisasi perjalanan dinas berbasis microsoft visual studio 2010 dan mysql digambarkan melalui entity relation diagram sebagai berikut: 


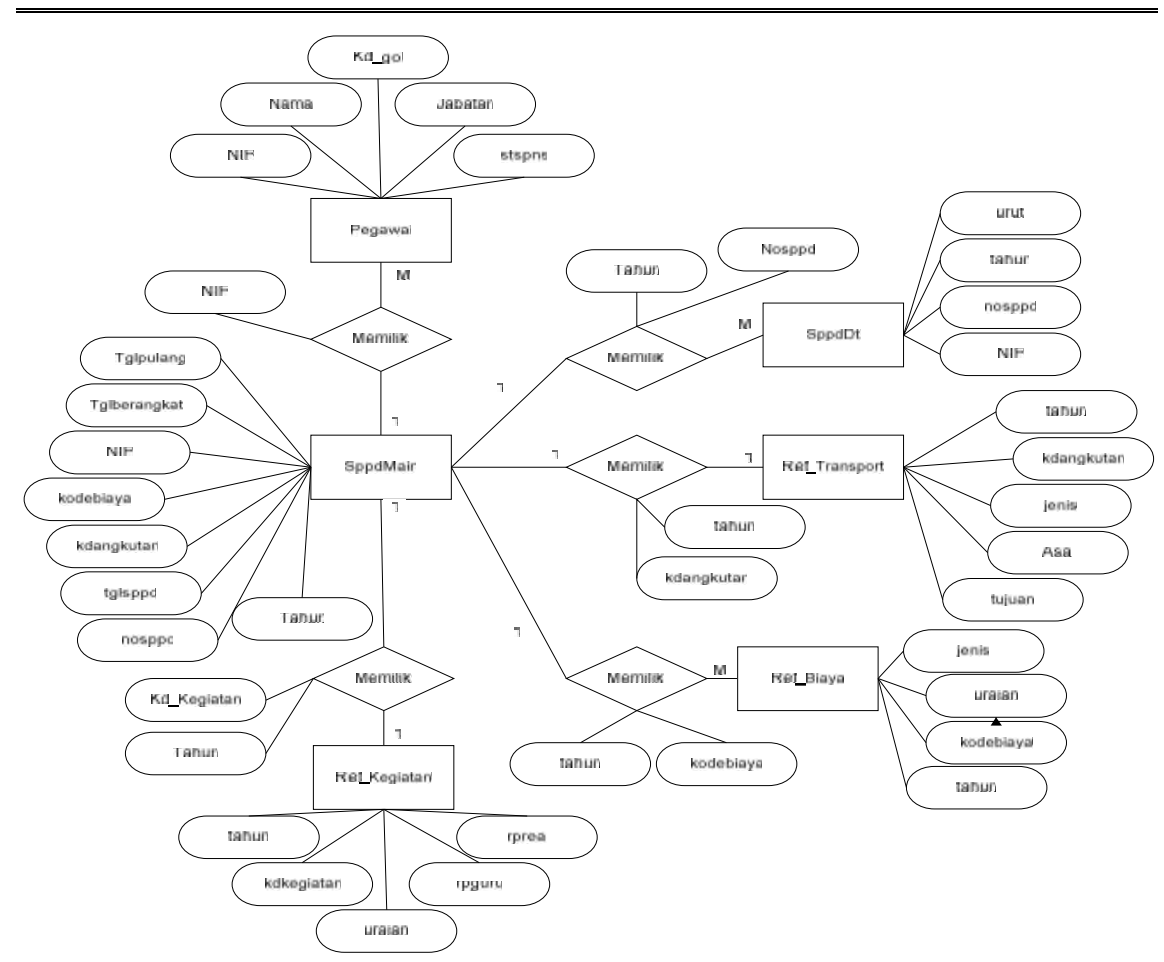

Gambar 1. Entity Relation Diagram

\section{B. Tahap Perancangan Proses}

Pada tahap perancangan proses, tampilan sistem realisasi perjalanan dinas berbasis microsoft visual studio 2010 dan mysql digambarkan melalui data flow diagram (dfd) sebagai berikut: 


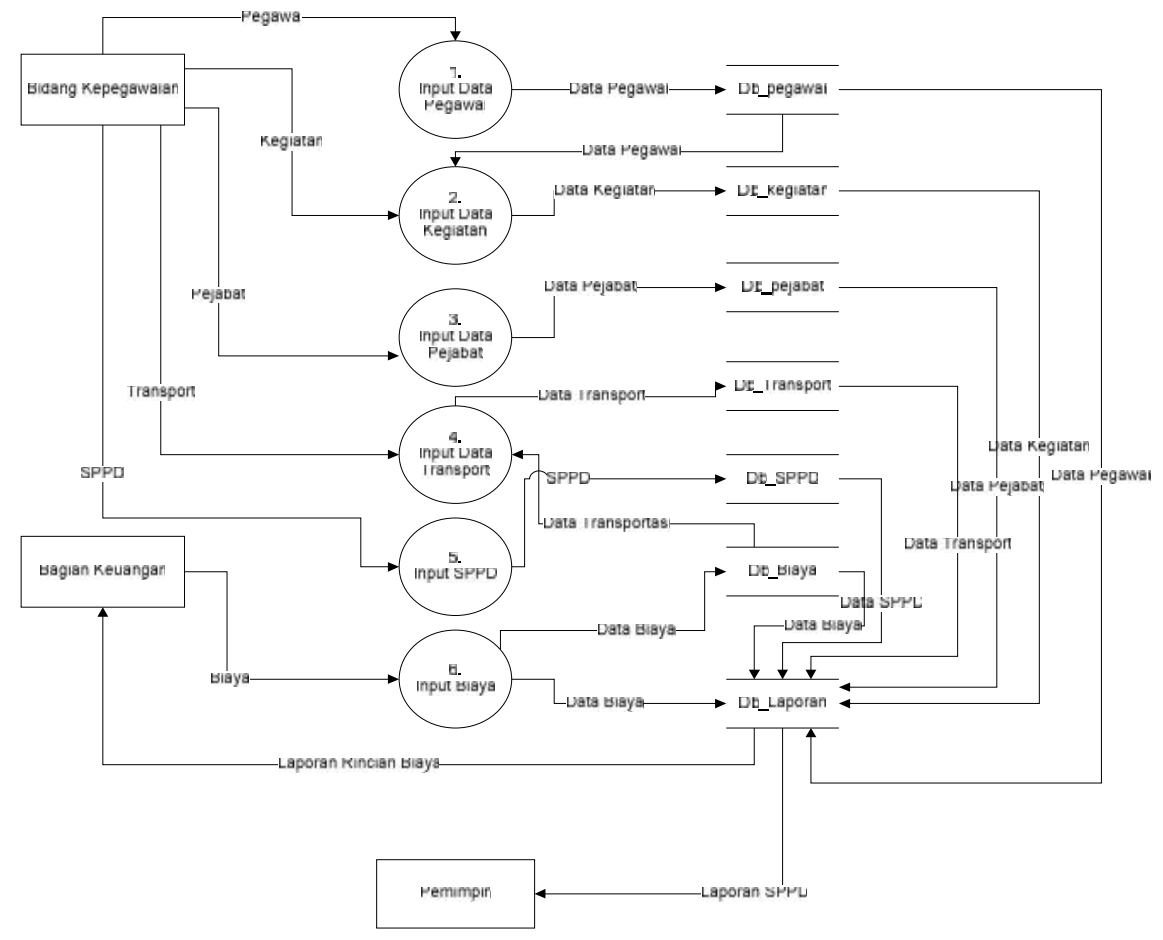

Gambar 2. Data Flow Diagram

\section{Tahap Perancangan Sistem}

Pada tahap perancangan sistem, tampilan sistem realisasi perjalanan dinas berbasis microsoft visual studio 2010 dan mysql digambarkan melalui flowchart sebagai berikut: 


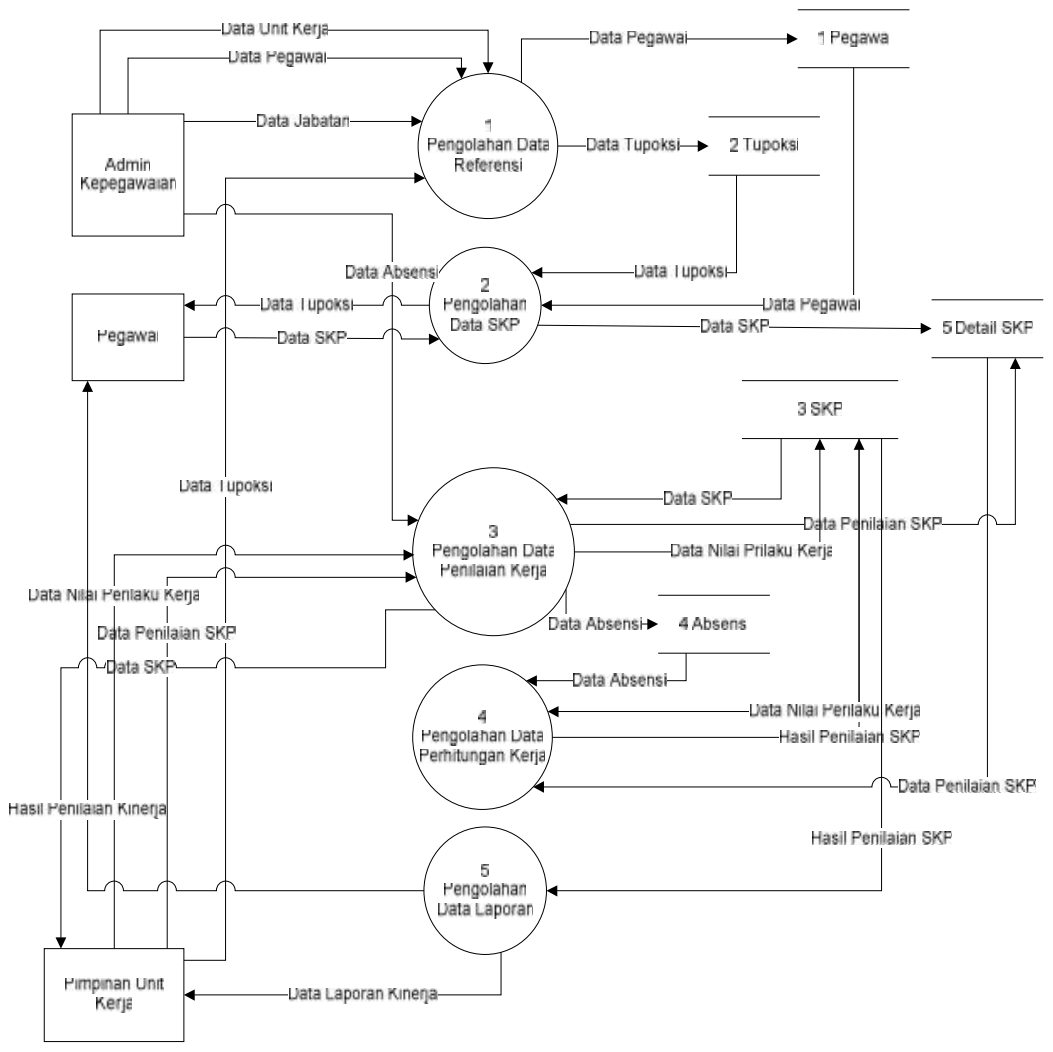

Gambar 3. Flowchart

\section{Hasil}

Berikut adalah hasil rancanagan program yang penulis susun dalam pembuatan aplikasi pembiayaan perjalanan pada dinas kesehatan kota pematangsiantar.

\section{Login}

Agar user dapat masuk ke sistem terlebih dahulu memasukan username dan password seperti gambar 4 berikut ini. 


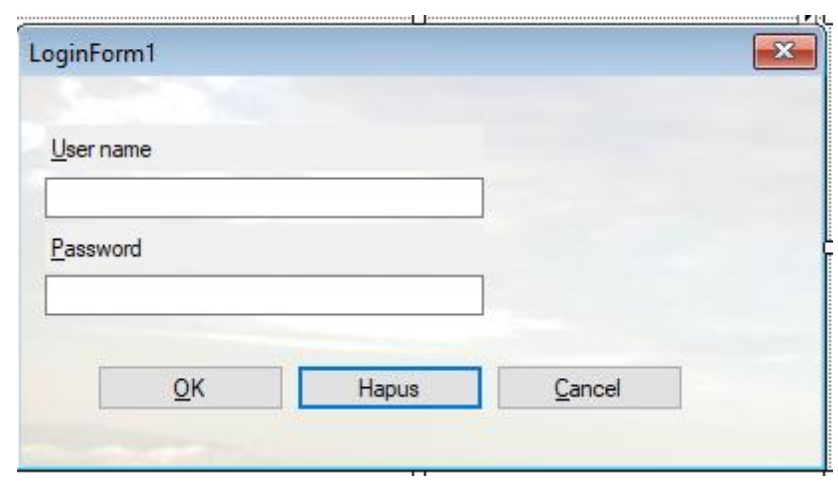

Gambar 4. Login Form

\section{Menu Utama}

Setelah users melakukan login maka akan muncul form menu utama. menu utama terdapat data autentifikasi, data master, data transaksi, dan laporan seperti gambar 5 .
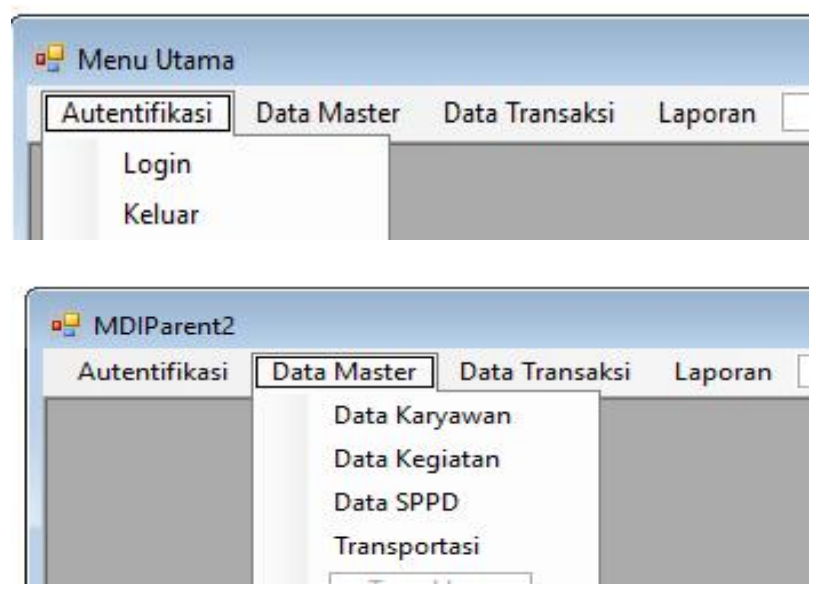

Gambar 5. Tampilan Menu Utama 
Rancang Bangun Sistem Informasi Pembiayaan Perjalanan Dinas pada Dinas Kesehatan Kota Pematangsiantar

\section{Data Karyawan}

Berikut adalah tampilan dari form data karyawan seperti pada gambar 6.

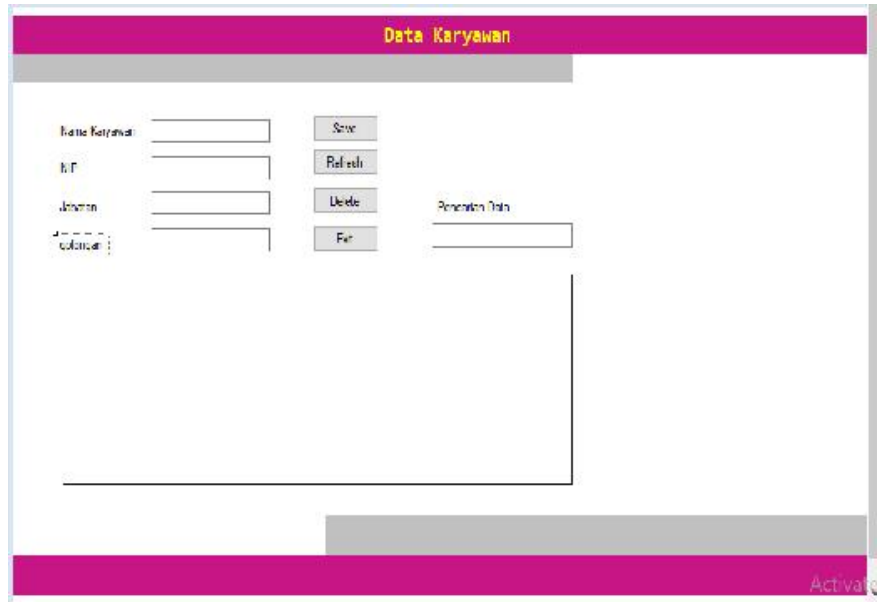

\section{Gambar 6. Form Data Karyawan}

\section{Data Kegiatan}

Setelah kita mengisi data karyawan yang akan melakukan perjalanan dinas selanjutnya kita masuk pada form data kegiatan seperti gambar 7 .

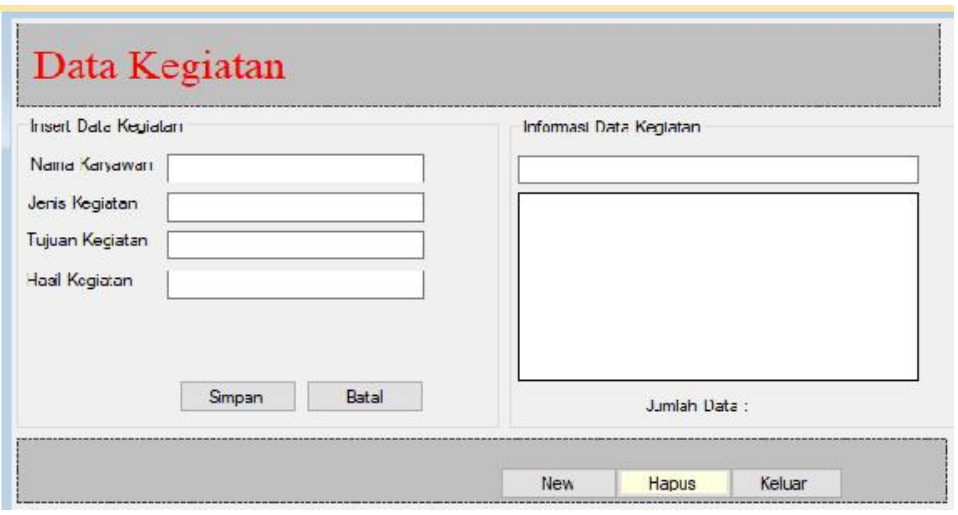

Gambar 7. Form Data Kegiatan 


\section{Data SPPD}

Selanjutnya kita akan mengisi form data sppd seperti gambar 8 .

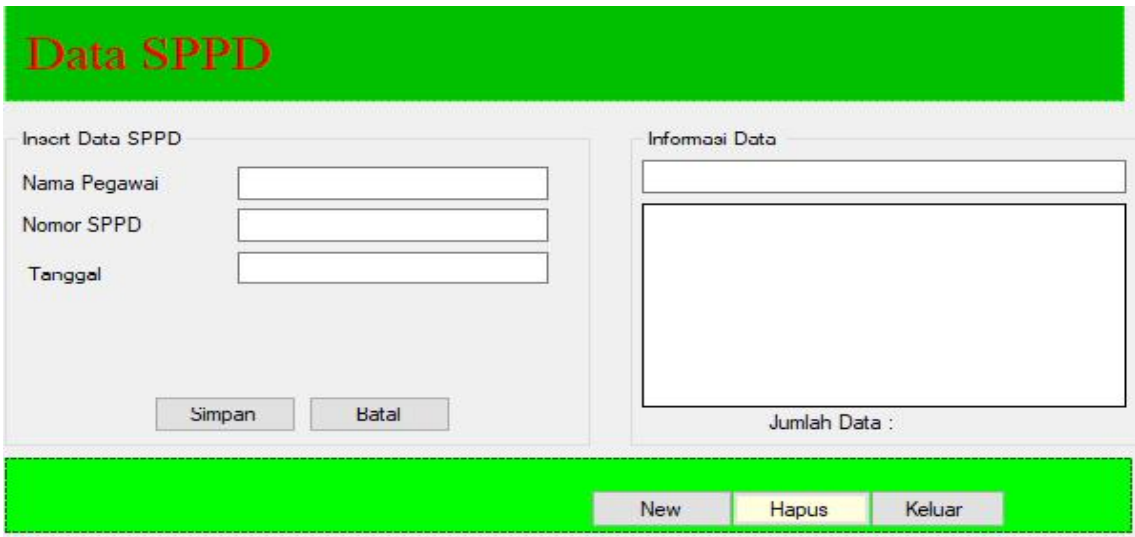

Gambar 8. Form Data SPPD

\section{Data Transportasi}

Pada form tampilan utama terdapat data transportasi, berikut adalah form data transportasi.

\section{Form Data Transportasi}

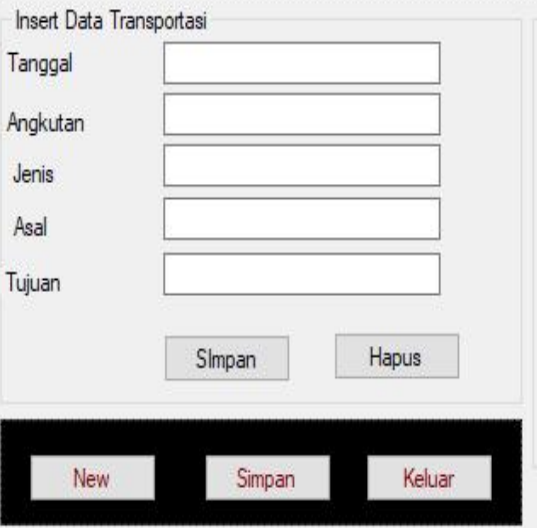

Informasi Data Transportasi

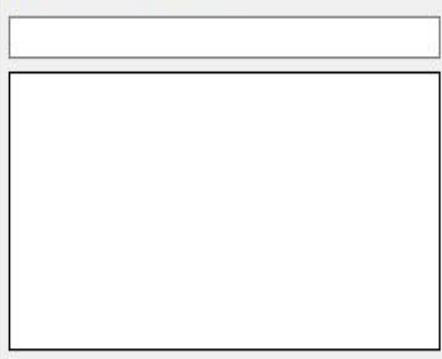

Jumlah Data

Gambar 9. Form Data Transportasi 
Rancang Bangun Sistem Informasi Pembiayaan Perjalanan Dinas pada Dinas Kesehatan Kota Pematangsiantar

Data Transaksi

Berikut adalah form data transaksi seperti gambar 10 .

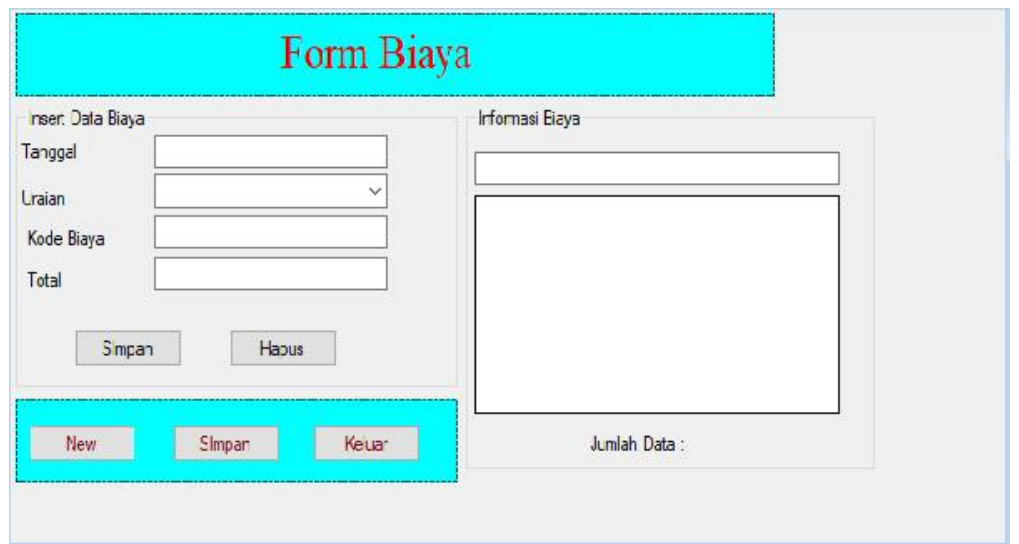

\section{Gambar 10. Form Biaya}

\section{Laporan}

Berikut adalah form tampilan laporan keuangan pada perjalanan dinas kesehatan kota pematangsiantar.

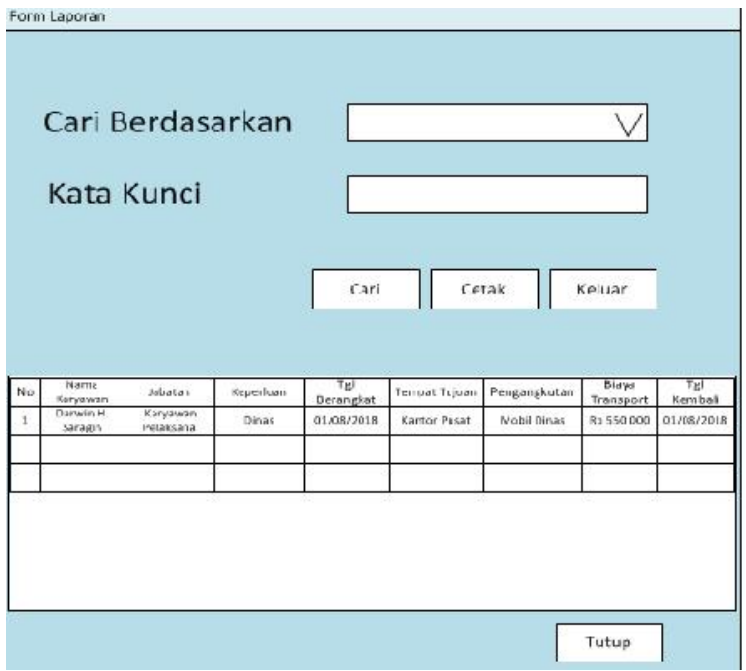

Gambar 11. Form Laporan 


\section{Kesimpulan dan Saran}

Kesimpulan yang dapat penulis simpulkan setelah melakukan pengamatan di dinas kesehatan Kota Pematangsiantar, penulis dapat mengambil kesimpulan dan saran untuk menilai seberapa jauh kelebihan dan kekurangan didalamnya:

1. Dengan menerapkan sistem informasi VB Net dan Database $M y S q l$, maka diharapkan pengumpulan dan pengolahan data lebih cepat, efektif, dan akurat.

2. Dalam pembuatan laporan keuangan mengenai pembiayaan perjalanan dinas pada dinas kesehatan Kota Pematangsiantar lebih struktur.

3. Dalam penyimpanan data lebih mudah dan lebih aman Dengan menggunakan aplikasi VBNet dan Database MySql, dapat meminimaliskan kesalahan dalam menginput data.

Saran yang diusulkan penulis untuk meningkatkan sistem perhitungan pembiayaan perjalanan dinas pada dinas kesehatan Kota pematangsiantar, untuk memperbaiki kinerja dan sistem dalam mengatasi masalah-masalah yang ada dalam sistem ini, penulis memiliki beberapa saran antara lain :

1. Penulis menyarankan agar perusahaan ikut mengembangkan sistem usulan ini sehingga proses perhitungan dan laporan pada pembiayaan perjalanan dinas pada dinas kesehatan Kota Pematangsiantar dapat menghasilkan laporan yang akurat.

2. Memperbaiki serta meningkatkan sistem single user agar menjadi sistem yang multi user.

Sistem ini masih sangat sederhana sehingga perlu penggembangan seperti sistem yang berbentuk WEB dan pengembangan aplikasi lainnya. 


\section{Daftar Pustaka}

Aginta, Geniusa. 2013. “Pembuatan Sistem Informasi Perjalanan Dinas Kantor Wilayah Direktorat Jenderal Pembendaharaan (SIPD-Kanwil DJPBN)." JURNAL TEKNIK POMITS 2(2): 36670.

Maharani A. Onibala, Ventje Ilat, and Lintje Kalangi. 2014. "Evaluasi Sistem Dan Prosedur Akuntansi Pengeluaran Kas Belanja Langsung Pada Dinas Pekerjaan Umum Kabupaten Minahasa." Jurnal EMBA 2(2): 1691-1701.

Priyanti, Dwi, and Siska Iriani. 2013. "Sistem Informasi Data Penduduk Pada Desa Bogoharjo Kecamatan Ngadirojo Kabupaten Pacitan." IJNS - Indonesian Journal on Networking and Security: 55-61.

Ramadhani, Syaifudin, Urifatun Anis, and Siti Tazkiyatul Masruro. 2013. “Rancang Bangun Sistem Informasi Geografis Layanan Kesehatan Di Kecamatan Lamongan Dengan PHP MySQL." Jurnal Teknika 5(2): 479-84.

Suhendro, Dedi. 2017. "Perancangan Dan Implementasi Realisasi Anggaran Pendapatan (Studi Kasus : Pengadilan Negeri Klas IB Pematangsiantar)." In , 30-36. 